\title{
Dissertações do Programa de Pós-Graduação em Antropologia Social da UFPR - 2013
}

\section{Caroline Glodes Blum}

Professora orientadora: Selma Baptista

Título: Carnaval curitibano: o lugar de uma festa popular na cidade.

Data da defesa: $18 / 11 / 2013$

Resumo: As questões que abordarei neste trabalho decorrem da pesquisa etnográfica realizada com as escolas de samba participantes dos carnavais de Curitiba (PR) entre 2008 e 2013. A complexa experiência dos membros das escolas de samba traz questões interessantes para pensarmos não somente o carnaval em si, mas também coloca desafios sobre como pensar a cidade, seu imaginário, suas disputas, segregações e usos dos espaços públicos. Neste sentido, salientam- se as questões relacionadas aos espaços intervalares, às mediações e negociações que ocorrem no espaço urbano entre as variadas esferas (a oficial, a cotidiana e performática), de forma dinâmica. Ao apreendermos o carnaval não apenas em seu momento de entretenimento, inserimos esta manifestação na arena de disputas, que é o concurso carnavalesco em sua própria natureza, mas também uma arena de disputas das manifestações culturais populares na "agenda cultural" da cidade de Curitiba, em que o carnaval é uma delas e, como pretendo demonstrar, por razões muito específicas.

Palavras-chave: carnaval; festa popular; escola de samba; Curitiba.

\section{Christopher Augusto Carnieri}

Professor orientador: Paulo Renato Guérios

Título: A italianidade em movimento: travessias e olhares

Data da defesa: 10/09/2013

Resumo: Este trabalho analisa o que buscam os brasileiros de ascendência italiana quando vão à Itália e o que encontram ao chegar lá. Primeiramente é estudada a formação da italianidade na Itália através da análise de questões sobre os nacionalismos do século XIX e o processo de construção da nação italiana. 
Posteriormente é estudada a formação da italianidade brasileira através da análise do processo migratório e da colonização até a renovação do elo com a Itália, momento o qual os descendentes buscam na viagem à Itália uma forma de estabelecer um contato direto com a cultura italiana. $\mathrm{O}$ trabalho de campo descreve como a experiência de ida à Itália se constitui enquanto um processo de construção identitária, o qual pode funcionar como uma nova leitura da italianidade.

Palavras-chave: análise intercultural; identidade; italianidade; migração.

\section{Elton Colini Gonçalves Zimmermann}

Professora orientadora: Liliana de Mendonça Porto

Título: “Tolo é aquele que diz que tempos bons foram os do passado": juventude e pentecostalismo em uma Bola de Neve Church

Data da defesa: $08 / 11 / 2013$

Resumo: Surgida no efervescente contexto das inovações no campo pentecostal brasileiro na passagem do século XX para o XXI, a Bola de Neve Church é nacionalmente conhecida como a "igreja dos surfistas". Neste trabalho, analiso, a partir de pesquisa de campo realizada na sua igreja de Paranaguá, Paraná, as formas como não apenas o surf, mas um amplo conjunto de imagens culturais da juventude é mobilizado, tendo suas imagens ressignificadas na constituição da experiência religiosa. Busco mostrar como, na igreja, a juventude não é nem depreciada nem apenas utilizada como estratagema de atração de novos fieis, mas, sim, reorientada de forma que ela mesma passe a fornecer os termos da experiência religiosa. Assim, ela dá novo sentido à condição de juventude ao mesmo tempo em que também redefine as formas de ser evangélico. Ao justapor estes dois universos, a igreja acaba trazendo transformações em ambos, pondo em xeque presunções acerca dos limites de um e de outro.

Palavras-chave: pentecostalismo: juventude; Bola de Neve Church; Paranaguá.

\section{Fernando José Ciello}

Professora orientadora: Liliana de Mendonça Porto

Título: Saúde mental, loucura e saberes: reforma psiquiátrica, interações e identidades em uma clínica-dia Data da defesa: $18 / 11 / 2013$

Resumo: O objetivo principal desta dissertação é oferecer uma leitura antropológica das práticas de tratamento para sujeitos em sofrimento psíquico a partir de pesquisa etnográfica conduzida entre 2011 e 2013 em uma clínicadia do sul do Brasil. A dissertação toma a reforma psiquiátrica como um corpo de práticas e de discursos que, tendo se originado em um período anterior, orienta políticas públicas de saúde mental e ações de profissionais deste campo. A partir da ideia nativa de que as relações sociais são relevantes para a terapêutica e a para a melhora da saúde dos pacientes, busca-se apontar as conexões e interpretações nativas entre este contexto de reforma e a percepção de relações sociais e identidades como principais objetos e campos de atuação dos terapeutas. Para dar conta destas discussões, a dissertação se referencia em teorias sobre interações sociais 
e identidade e a produção cotidiana e dinâmica de categorias e representações de relevância para as ações sociais. A análise, situada em distintos momentos do texto, está acompanhada da descrição das atividades de profissionais e pacientes, e evidencia uma constante transformação da identidade de paciente, e uma manipulação de aspectos estigmáticos de suas identidades, o que conduz a processos dinâmicos e multirreferenciados de classificação e de simbolização das categorias médicas e dos próprios indivíduos. Observou-se que o tratamento empreendido traz para o cotidiano dos sujeitos da pesquisa e para as práticas terapêuticas uma busca por resolução de problemas principalmente nos campos do trabalho, da família e da religião; bem como da reiteração da noção de pessoa moderna como indivíduo. Sugere-se, ao final, que haja a necessidade de abordar o fenômeno do tratamento de sujeitos em sofrimento psíquico atual como conjuntamente referenciado pelo discurso abrangente de reforma e de multiplicidade de saberes, bem como pela problemática da determinação interativa e cotidiana de categorias importantes para este campo. Entende-se que a noção de pessoa moderna individualizada seja crucial para entender este campo e que a partir do estudo deste contexto específico esta noção possa ser ampliada e complexificada, sobretudo ao considerar a associação entre as práticas terapêuticas e a noção de desenvolvimento pessoal como critério de saúde mental.

Palavras-chave: clínica-dia; saúde-mental; identidade; saberes; noção de pessoa.

\section{Guilherme Nanini da Silva Oliveira}

Professora orientadora: Liliana de Mendonça Porto

Título: "Ganha bonito, perde bonito": honra e corporalidade no kendo paulistano

Data da defesa: $11 / 12 / 2013$

Resumo: Esta etnografia tem como objeto a hierarquia no kendo em São Paulo. A pesquisa foi realizada no Bunkyo dojo, academia sediada na Sociedade Brasileira de Cultura Japonesa e de Assistência Social, uma grande associação nipo-brasileira no bairro da Liberdade. Esta instituição preconiza a divulgação e a preservação da cultura japonesa no Brasil e abriga o Museu da Imigração Japonesa, uma biblioteca, o Centro de Estudos NipoBrasileiros e muitas outras instituições. O kendo é uma prática oriunda do Japão, na qual se luta com espadas de bambu, utilizando um equipamento de proteção. O kendo faz parte do conjunto de práticas denominado budo, que corresponde às práticas marciais japonesas, como karate, judo e aikido. O problema proposto foi analisar como a hierarquia opera para além dos marcadores institucionais reificados. Esse problema leva em consideração que a hierarquia é a estrutura ordenadora da prática e que regula diversas relações de trocas.

Palavras-chave: Kendo; Budo; Comunidades de prática; Capital; Honra; Corpo. 


\section{Henrique Ressel}

Professor orientador: Miguel Carid Naveira

Título: Cerimônias nativas: tradição e inovação no Fogo Sagrado de Itzachilatlan

Data da defesa: $27 / 02 / 2013$

Resumo: A presente dissertação trata da prática de cerimônias nativas no contexto contemporâneo do xamanismo urbano, a partir de pesquisa de campo realizada com um grupo fundador da primeira Igreja Nativa Americana no país. Este grupo se apresenta como representante de uma "Tradição Espiritual Indígena da América", sustentando que essa tradição tem origem em povos nativos. A constituição dessa Igreja no país é decorrente de um movimento de expansão de uma Igreja Nativa Americana com sede nos Estados Unidos (Chicago/IL). A formalização dessas cerimônias como Igrejas se deu em razão da necessidade de regulamentar essas práticas espirituais nativas junto ao Estado, onde foi criada no início do século passado a Native American Church nos EUA. As lideranças, nacional e estrangeira, contam que essa tradição foi transmitida pelos nativos, no seio de suas comunidades, de forma direta e oral, por meio de ritos cerimoniais, que são conduzidos e oficializados por líderes preparados e delegados para tal. O trabalho de campo se desenvolveu a partir do grupo central pesquisado, abrangendo uma rede de atores centrais que estabelece um circuito ao redor da prática das cerimônias nativas e compõe os contextos de construção dos discursos de tradição nativa. A dissertação aborda uma discussão sobre tradição e religião como memórias do passado, e também apresenta o panorama mais abrangente da Nova Era e das novas religiosidades, contexto no qual está inserida a prática das cerimônias nativas no contexto urbano contemporâneo.

Palavras-chave: cerimônias nativas; ritual; tradição; Igreja Nativa Americana.

\section{Lucas Cimbaluk}

Professor orientador: Miguel Carid Naveira

Título: A criação da aldeia Água Branca na Terra Indígena Kaingang Apucaraninha: "política interna", moralidade e cultura

Data da defesa: 01/07/2013

Resumo: Na Terra Indígena Apucarana, ou Apucaraninha como é usualmente chamada, de etnia kaingang, localizada ao norte do Estado do Paraná, houve, em 2011, a criação de uma nova aldeia, denominada Água Branca. Esta aldeia, diferentemente das outras três ali já existentes (Sede, Barreiro e Serrinha), pretendia uma autonomia política em relação ao cacique que representava a Terra Indígena como um todo. Esta ruptura, significativa no contexto kaingang, onde se defende a unidade político-territorial baseada atualmente na Terra Indígena, é tratada neste trabalho, a partir de narrativas sobre o fato bem como análise de suas consequências durante o período de trabalho de campo junto ao grupo. Trato aqui de três elementos chave que envolveram o processo de criação e a manutenção da diferenciação entre as aldeias: a "política interna", relativa à característica faccional dos kaingang e as articulações políticas e sociais relacionadas a ela; a moralidade, como elemento diretamente relacionado à chefia mas também às formas de convivência na comunidade, representadas através, 
relacionando a tradição, os conhecimentos e práticas e o próprio ser kaingang, a diferenciar-se dos brancos. Em um contexto vivido pelos moradores da Terra Indígena envolvendo uma indenização por uma antiga usina hidrelétrica na área, bem como a construção de uma nova usina em rio adjacente, com suas compensações então em negociação, analiso como o movimento de criação da nova aldeia, com símbolos, discursos e práticas relativas à moralidade e à cultura permitem articulações políticas e formas de sociabilidade que indicam a necessidade de um reforço da indianização, contra um possível tornar-se branco. Esta indianização, para além de ser contraposta ao branco, é, então, contraposta ao próprio outro indígena, representado na outra aldeia, favorecendo as transformações do ser indígena, do ser kaingang.

Palavras-chave: Terra Indígena Apucaraninha; política.

\section{Maria Helena Amorin Pinheiro}

Professora orientadora: Laura Pérez Gil

Título: A Emergência do Ritual do Kiki no Contexto Contemporâneo

Data da defesa: 01/10/2013

Resumo: Este trabalho pretendeu explicitar e refletir sobre os fatores, contextos e perspectivas dos diferentes agentes envolvidos na emergência contemporânea do ritual do kiki entre os Kaingang de Xapecó e Condá, âmbito configurado pela dicotomia entre ritual tradicional/autêntico e ritual atual revitalizado/não autêntico. Os estudos evidenciaram a permanência da funcionalidade ritual em sua eficácia simbólica, política e social, paralelamente a um processo de ampliação de suas formas de realização, configurado com novos atores do contexto de interatividade, e novas situações como escassez de rezadores e kuiãs, descontinuidade de realização por longos períodos, necessidade de expansão das relações para com o mundo exterior, e criação de espaços para comunicação de demandas políticas. Os Kaingang de Xapecó e Condá introduziram nos rituais do kiki novos significados e interpretações da tradição, demonstrando que os rituais contemporâneos não se configuram exclusivamente com elementos herdados de gerações anteriores, mas que agregaram transformações e inovações que determinaram a coexistência atual da tradição e criação no contexto histórico.

Palavras-chave: Kaingang; ritual kiki; autenticidade; tradição; inovação; política de indianidade; eficácia simbólica, política e social.

\section{Mauro Leno Silvestrin}

Professor orientador: Lorenzo Gustavo Macagno

Título: O movimento pró-canábis no Rio de Janeiro (2002-2012). Experiências, trajetórias e atores

Data da defesa: $28 / 02 / 2013$

Resumo: O presente trabalho tem por escopo a análise das trajetórias de militantes pró legalização da canábis no Rio de Janeiro. Através da reconstrução histórica do movimento Marcha da Maconha, discorreremos sobre quem são os militantes que o compõe, bem como quais são suas práticas e objetivos. Tais militantes se utilizam das tecnologias de comunicação e da internet na legitimação da demanda por uma alteração no caráter legal a 
que o vegetal está sujeito. E, através de pequenos empreendimentos, ligados a "cultura canábis", ou de cargos eletivos, configuram a primeira militância profissional em torno do tema no país.

Palavras-chave: movimento pró-canábis; marcha da maconha

\section{Sabrina de Assis Andrade}

Professor orientador: Laércio Loiola Brochier

Título: Etnoarqueologia Mbya Guarani no Tekoa Pindoty, litoral do estado do Paraná

Data da defesa: 29/10/2013

Resumo: Esta dissertação tem como finalidade apresentar as discussões e os resultados de uma análise etnoarqueológica realizada junto aos Mbya Guarani do Tekoa Pindoty ou Terra Indígena Ilha da Cotinga, no litoral do Estado do Paraná. Objetivou-se compreender qual a relação estabelecida entre os indígenas e este local, sob o ponto de uma pesquisa que integrasse estudos arqueológicos e etnológicos buscando novos referenciais para a reflexão sobre a cultura material remanescente nessas áreas. Segundo os nativos, este território é reconhecido como terra tradicional indígena devido, entre outros, à presença de vestígios de seus ancestrais o que inclui objetos e áreas de valor histórico-arqueológico atuais, mas também um conjunto de elementos e disposições que marcam as relações entre este lugar e o modo de ser guarani. $\mathrm{O}$ estudo partiu de pesquisas bibliográficas e levantamentos de campo, estes últimos realizados com a colaboração dos Mbya Guarani. Os levantamentos bibliográficos (arqueológicos e etnohistóricos) apontaram para uma ocupação regional por povos de tradições indígenas ceramistas, normalmente associadas aos ancestrais dos guaranis e tupis. Quanto às pesquisas de campo, constatou-se que as ilhas possuem sítios e vestígios arqueológicos (ex. sambaquis, cerâmicas manufaturadas e louças históricas, ruínas de alvenaria de pedra, etc), muitos dos quais dispostos nas áreas das atuais moradias dos Mbya, nos locais de abandono temporário e nas vias de circulação. Compreender a relação entre os Mbya Guarani e este local, só foi possível a partir de uma proposta colaborativa que contemplou as categorias nativas de território, as quais englobam aspectos físicos, econômicos e simbólicos. A noção de território nativase dá na relação dos seguintes conceitos: teko + nhandereko $=$ tekoa, que seria a cultura + território = vida Mbya Guarani. Assim, foi possível perceber que quando os Mbya falam sobre a presença de vestígios de seus ancestrais, nem sempre eles estão falando da cultura material, pois muitas vezes, a relação deles com determinados lugares se dá em outra percepção da realidade, onde são consideradas as questões cosmológicas referentes à cultura tradicional indígena. Por sua vez, a inserção dos objetos, moradias e processos modificadores da paisagem relacionados à ocupação Mbya, permitiu visualizar os processos formativos de sítios arqueológicos como palimpsestos acumulativos e de significados. Neste sentido, as reocupações são processos comuns, pois mesmo em um ambiente bem delimitado pelo caráter da insularidade, existem muitos acessos "restritos", que não são ditados pela mera relação entre territórios ocupados e recursos naturais. Sob o ponto de vista arqueológico, as áreas constantemente antropizadas e 
resignificadas em função de determinados remanescentes "herdados" parecem constituir papel importante no processo de ocupação Mbya do Tekoa Pindoty.

Palavras-chave: etnoarqueologia; Mbya Guarani; tekoa Pindoty.

\section{Tatiana Fatuch Rabinowitz Mencier}

Professor orientador: Paulo Renato Guérios

Título: Tom, Jobim \& Antônio Brasileiro: um olhar sobre a identidade brasileira em uma trajetória e obra entre mundos

Data da defesa: $22 / 11 / 2013$

Resumo: Neste estudo, busca-se associar o tema da identidade brasileira à trajetória e obra do compositor Antonio Carlos Jobim. Com base no diálogo entre diferentes fontes teóricas e empíricas, buscou-se restituir o contexto entre dois ou mais mundos no qual Tom Jobim se situava para realizar um estudo aprofundado de duas fases de sua trajetória: o período em que o compositor se destaca através da bossa nova (1958 - 1970) e a década de 1970 (1970-1980) em que pode-se observar uma aproximação com temas relacionados à natureza, ao folclore e à literatura brasileira. As construções em torno da identidade brasileira ao longo do séc. XX apresentam um cerne dicotômico em comum que aparece como a chave para a compreensão das percepções e recepções da obra de Tom Jobim, em um primeiro momento associada à bossa nova e ao longo de toda sua carreira a sua trajetória entre o Brasil e o exterior. A bossa nova e Tom Jobim - enquanto um de seus principais idealizadores - vêm representar musicalmente o ideal de modernização e civilização almejado pela nação mas, por outro lado, devem se confrontar à busca pela contraposição em relação ao mundo considerado civilizado por meio de uma ideia de autenticidade dentro da qual o gênero não se encaixa segundo a visão de uma parte da crítica musical. O estudo mostra as idas e vindas do compositor entre dois universos simbólicos - Brasil e Estados Unidos - e como o imaginário em torno da identidade brasileira e a noção de autenticidade podem ser interpretados a partir de ângulos distintos. Constata-se que no Brasil, a partir da década de 1960, permeava uma visão político-ideológica que teve direta influência sobre a percepção da obra do compositor ao passo que, nos Estados Unidos, a recepção da bossa nova e de Tom Jobim se apoia em uma visão mercadológica. As respostas em relação a ambas as visões se manifestam na produção artística do compositor a partir da década de 1970 quando desenvolve um novo imaginário sonoro sobre o Brasil que nasce de um olhar singular decorrente de sua trajetória entre mundos.

Palavras-chave: identidade brasileira; música popular brasileira; bossa nova; Antônio Carlos Jobim; trajetória entre mundos. 


\section{Tiemi Kayamori Lobato da Costa}

Professora orientadora: Ciméa Barbato Bevilaqua

Título: Indígenas e não indígenas na administração pública: uma etnografia da Secretaria de Estado para os Povos Indígenas do Estado do Amazonas

Data da defesa: $29 / 11 / 2013$

Resumo: O presente trabalho consiste em uma etnografia do processo de estar e fazer uma administração pública tanto por servidores indígenas quanto não indígenas. Tomo como ponto de reflexão uma instituição brasileira: a Secretaria de Estado para os Povos Indígenas (SEIND), órgão vinculado ao poder executivo do estado do Amazonas, Brasil, criado a partir da Lei 3.403 de 2009. Busca-se refletir sobre o recente protagonismo de agentes estatais indígenas na administração pública e, assim, voltar o olhar para a uma forma estatal que emerge a partir do reconhecimento da diferença. Através da etnografia foi possível notar que a forma com que os servidores indígenas se percebem em tal processo implica na continuidade de um projeto político que, até então, havia tido seus principais desdobramentos através de organizações e associações vinculadas ao "movimento indígena". Ao mesmo tempo em que o surgimento da SEIND possibilita a ocupação de um lugar de poder inédito na estrutura estatal, estar em tal posição também significa entrar em consonância com um novo universo político e certa ordem e forma da organização estatal brasileira. $\mathrm{O}$ acompanhamento das atividades cotidianas na SEIND demonstrou que o imbricamento entre diferentes formas de estar na administração pública imprimem grande fluidez às concepções de "Estado" e de "indianidade". Assim, as rotinas administrativas, a percepção dos servidores a respeito de seus trabalhos, e as interações interinstitucionais, recriam e atualizam tal dualidade de diferentes formas: "Estado" e "índios", "governo" e "movimento indígena", "técnica" e "política", "indígenas" e "não indígenas". A articulação de ambos universos políticos demonstrou grande criatividade por parte dos servidores que, frente ao baixo orçamento da instituição, utilizam a experiência adquirida nas associações e organizações indígenas para fundamentar diferentes estratégias de gestão. Argumento que esse espaço de negociação entre um pólo supostamente "indígena" e outro "Estatal", ou seja, esta permanente confluência, acabaria por produzir a SEIND em sua especificidade enquanto forma de administração pública e enquanto projeto político indígena.

Palavras-chave: administração pública; indígenas; estado. 